\title{
Effects of Caerulein on the Apical Cytoskeleton of the Pancreatic Acinar Cell
}

Mark S. O'Konski and Stephen J. Pandol

Department of Medicine, Veterans Administration Medical Center, San Diego, California 92161; and University of California, San Diego, California 92093

\begin{abstract}
In this study experiments were performed to correlate the rate of digestive enzyme secretion to morphologic observations of the apical cytoskeleton using dispersed rat pancreatic acini with various concentrations of caerulein. Caerulein at concentrations of $10 \mathrm{pM}$ to $0.1 \mathrm{nM}$ stimulated increasing rates of secretion of amylase, a digestive enzyme. Greater concentrations of caerulein caused progressively less amylase secretion. Transmission electron microscopy demonstrated several characteristics of the apical cytoskeleton in untreated acini that were altered with the "inhibitory" concentrations of caerulein. In control acini and acini stimulated with concentrations of caerulein up to $0.1 \mathrm{nM}$, the micrographs reveal an apical actin network extending into microvilli, an intermediate filament band, and electron-dense structures contained in both the actin filament network and the intermediate filament band. With concentrations of caerulein $>0.1 \mathrm{nM}$, these structures were progressively ablated. The findings with respect to the actin filament network were confirmed with light microscopic observations of dispersed acini stained with rhodamine-phalloidin. These results indicate that caerulein has marked morphologic effects on the pancreatic acinar cell cytoskeleton and that the cytoskeletal changes may modulate the secretory response. (J. Clin. Invest. 1990. 86:1649-1657.) Key words: cholecystokinin • actin microfilaments $\bullet$ intermediate filaments • microtubules $\cdot$ amylase
\end{abstract}

\section{Introduction}

Caerulein, a decapeptide originally extracted from the skin of the amphibian Hyla caerulea, stimulates digestive enzyme secretion from the pancreatic acinar cell by interacting with the cholecystokinin $(\mathrm{CCK})^{1}$ receptor (1). Stimulation of secretion is mediated by changes in cellular phospholipid and calcium metabolism (2-16). With concentrations of CCK and caerulein greater than $\sim 0.1 \mathrm{nM}$, secretion is progressively less than maximal (1). The mechanisms of this inhibition are unknown. It has long been postulated that the apical (or cortical) network of actin microfilaments ("terminal web") may be involved in secretion by the pancreatic beta cell (17) and other secretory cells. In these studies we correlate changes in the apical cyto-

A preliminary report of this work was presented at the Annual Meeting of the American Gastroenterological Association in San Antonio, TX; May 1990 (1990. Gastroenterology. 98:A229 [Abstr.]).

Address reprint requests to Dr. O'Konski, Veterans Administration Medical Center(V-111-D), 3350 La Jolla Village Drive, San Diego, CA 92161.

Received for publication 28 December 1989 and in revised form 2 July 1990.

1. Abbreviation used in this paper: CCK, cholecystokinin.

The Journal of Clinical Investigation, Inc.

Volume 86, November 1990, 1649-1657 skeleton with rates of enzyme secretion caused by caerulein, to determine if alterations in the apical cytoskeleton are associated with changes in secretion. For this purpose we used dispersed pancreatic acini from the rat prepared by collagenase digestion of the pancreas. The acinus is the functional subunit in the exocrine pancreas responsible for digestive enzyme synthesis, storage, and secretion. Each acinus is composed of 10-20 acinar cells arranged around a central lumen. Digestive enzymes contained in apically located zymogen granules of the acinar cell are secreted into the lumen by exocytosis (18).

\section{Methods}

\section{Materials}

Sprague-Dawley rats (100-200 g) were from the National Cancer Institute (Frederick, MD). Hepes and bovine serum albumin (Fraction V) were from Boehringer Mannheim (Indianapolis, IN). Basal media (Eagle) amino acids (concentrated 100 times) and basal media (Eagle) vitamin mixture (concentrated 100 times) were from M.A. Bioproducts (Walkersville, MD). Glutamine was from Difco Laboratories Inc. (Detroit, MI). Phadebas amylase test was from Pharmacia Fine Chemicals (Piscataway, NJ). Purified collagenase (type CLSPA) was from Worthington Biochemical Corp. (Freehold, NJ). Caerulein, triethylenediamine, and soybean trypsin inhibitor were from Sigma Chemical Co. (St. Louis, MO). Rhodamine-labeled phalloidin was from Molecular Probes Inc. (Junction City, OR). Osmium tetroxide $\left(\mathrm{OsO}_{4}\right)$ and bismuth subnitrate were from Electron Microscopy Sciences (Fort Washington, PA). Uranyl acetate was from Ted Pella, Inc. (Tustin, CA). Poly/Bed 812 plastic was from Polysciences, Inc. (Warrington, PA). O.C.T. compound embedding medium was from Miles Laboratories Inc. (Elkhart, IN).

The standard incubation solution contained $24.5 \mathrm{mM}$ Hepes $(\mathrm{pH}$ 7.4), $98 \mathrm{mM} \mathrm{NaCl}, 2.5 \mathrm{mM} \mathrm{NaH}_{2} \mathrm{PO}_{4}, 6 \mathrm{mM} \mathrm{KCl}, 5 \mathrm{mM}$ Na pyruvate, $5 \mathrm{mM}$ Na fumarate, $5 \mathrm{mM}$ Na glutamate, $11.5 \mathrm{mM}$ glucose, $1.0 \mathrm{mM}$ $\mathrm{MgCl}_{2}, 0.5 \mathrm{mM} \mathrm{CaCl}, 2 \mathrm{mM}$ glutamine, $1.0 \%$ (wt/vol) bovine serum albumin, $0.01 \%(\mathrm{wt} / \mathrm{vol})$ soybean trypsin inhibitor, $1 \%(\mathrm{vol} / \mathrm{vol})$ amino acid mixture, and $1 \%$ (vol/vol) vitamin mixture.

\section{Methods}

Tissue preparation. Dispersed pancreatic acini were prepared from Sprague-Dawley rats using the procedure previously published for guinea pigs $(19,20)$.

Amylase release. Dispersed acini from the pancreas of one animal were suspended in $75-100 \mathrm{ml}$ of standard incubation solution. Aliquots of the suspended acini were incubated with the indicated concentrations of caerulein at $37^{\circ} \mathrm{C}$. Release of amylase from the pancreatic acini was measured as described previously (19-21). Amylase release was calculated as the percentage of the amylase activity in the acini at the beginning of the incubation that was released into the extracellular medium during the incubation.

Electron microscopy. For each experiment, dispersed acini were incubated in standard incubation solution containing the following concentrations of caerulein: $0,1.0 \mathrm{pM}, 10 \mathrm{pM}, 0.1 \mathrm{nM}, 1.0 \mathrm{nM}$, and 10 $\mathrm{nM}$. All incubations were at $37^{\circ} \mathrm{C}$. At the indicated time the acini were separated from the media in a $1.5-\mathrm{ml}$ centrifuge tube using a microfuge (Beckman Instruments, Inc., Palo Alto, CA) with 1-2 s of centrifugation. The cell pellet was resuspended in cold $\left(4^{\circ} \mathrm{C}\right)$ modified Karnovsky's fixative $(0.5 \%$ [vol/vol] glutaraldehyde and $1.5 \%$ [vol/vol] paraformaldehyde in $0.1 \mathrm{M} \mathrm{Na}$ phosphate buffer, $\mathrm{pH}$ 7.4) using a 
Pasteur pipette. After fixing for $10 \mathrm{~min}$ the acini were pelletted with centrifugation at $800 \mathrm{~g}$ for $10 \mathrm{~min}$. The acini were stored at $4^{\circ} \mathrm{C}$ until embedding (usually the next day). Before embedding, the pellets were washed three times ( $5 \mathrm{~min}$ each) in $0.1 \mathrm{M} \mathrm{Na}$ phosphate buffer ( $\mathrm{pH}$ 7.4). The cell pellets were then post-fixed in $2 \% \mathrm{OsO}_{4}$ for $1.5 \mathrm{~h}$, washed again with phosphate buffer, dehydrated in a graded series of increasing ethanol concentrations followed by propylene oxide, and then embedded in Poly/Bed 812 plastic. 80-nm sections were prepared using a microtome (model MT2-B; Sorvall Instruments, Newton, CT) and then stained with uranyl acetate (saturated solution in $50 \%$ ethanol and $\left.50 \% \mathrm{H}_{2} \mathrm{O}\right)$ and bismuth subnitrate $(0.4 \mathrm{mg} / \mathrm{ml})$. Observations were made on an 80-kV electron microscope (model EM-10; Carl Zeiss, Inc., Thornwood, NY) and photographs were taken on Kodak $31 / 4 \times 4$ inch $4489 \mathrm{film}$. The electron micrographs presented are representative of those observed from four separate experiments.

Rhodamine-phalloidin staining of actin filaments. Suspended acini were incubated at $37^{\circ} \mathrm{C}$ with the following concentrations of caerulein: $0.1 \mathrm{nM}, 10 \mathrm{nM}$, and control. At the indicated time acini were separated from the incubation solution in a $1.5-\mathrm{ml}$ tube using a microfuge (Beckman Instruments, Inc.) for 1-2 s of centrifugation. After removing the incubation solution, $100 \mu \mathrm{l}$ of O.C.T. embedding medium was added and the cell pellet was gently suspended in the O.C.T. compound using a Pasteur pipette with a sealed tip. The centrifuge tube was capped and immersed in liquid $\mathrm{N}_{2}$. Then, 4-6- $\mu \mathrm{m}$-thick frozen sections were prepared using a cryomicrotome (model 845, American Optical Corp., Buffalo, NY). The sections were placed on coated glass slides and allowed to air dry for 1-3 $\mathrm{h}$. They were then fixed for $2 \mathrm{~min}$ with cold $\left(4^{\circ} \mathrm{C}\right)$ modified Karnovsky's fixative $(0.5 \%$ glutaraldehyde and $1.5 \%$ paraformaldehyde in $0.1 \mathrm{M} \mathrm{Na}$ phosphate buffer, $\mathrm{pH} 7.4$ ), followed by three rinses using the standard incubation solution without albumin over $15 \mathrm{~min}$. The still moist sections were incubated with rhodamine-phalloidin $(20 \mathrm{U} / \mathrm{ml}$ in standard incubation solution without albumin) at room temperature in the dark for $30 \mathrm{~min}$ as described by Drenckhahn and Mannherz (22). The sections were then washed with three rinses of standard incubation solution without albumin of $10 \mathrm{~min}$ each. Coverslips were mounted over the sections with a drop of a mixture containing glycerol $(50 \%$, vol/vol), phosphate buffer $(50 \%, \mathrm{vol} / \mathrm{vol})$, and triethylenediamine $(0.25 \%$, wt/vol), the latter to diminish quenching of the rhodamine. Sections were observed on a Diaphot TMD-EF microscope (Nikon Inc., Garden City, NY) with epifluorescence using a G-2A filter cube and a ND-16 filter at the light source. 35-mm photographs were taken on Kodak T-Max 400 film. Exposure time and aperture were kept constant for each experiment. The micrographs presented are representative of observations made from seven separate experiments.

\section{Results}

As described previously (1) and illustrated in Fig. 1, caerulein causes amylase release from pancreatic acini. The threshold concentration for amylase release was $<10 \mathrm{pM}$ and maximal release occurred at $0.1 \mathrm{nM}$. With greater concentrations of caerulein there was progressive inhibition of amylase release.

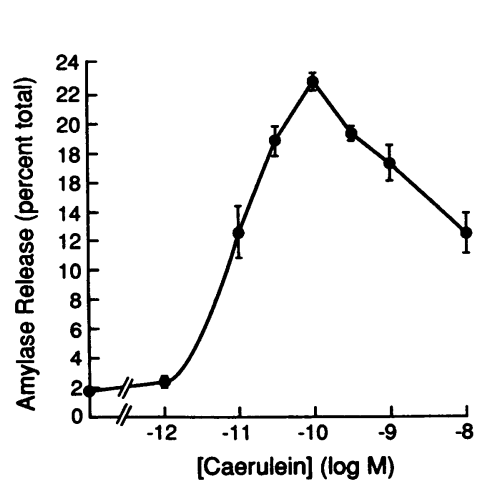

Figure 1. Effect of various concentrations of caerulein on amylase release from dispersed rat pancreatic acini. Aliquots of acinar suspension were incubated with the indicated concentrations of caerulein for 30 min. Amylase release during the incubation was determined as described in Methods. The results are the means $\pm S E$ of six experiments.
To determine the time course of amylase release with both the maximally effective concentration $(0.1 \mathrm{nM})$ and the inhibitory concentration of caerulein $(10 \mathrm{nM})$, we performed the experiment in Fig. 2. The results indicated that the difference in the rates of amylase release was detected as early as $3 \mathrm{~min}$. In experiments not shown, the rates of amylase release for these two concentrations of caerulein remained different for up to $30 \mathrm{~min}$.

To explore the ultrastructural effects of caerulein we performed routine transmission electron microscopy on dispersed acini treated with the various concentrations of caerulein. The electron micrographs in Fig. 3 illustrate pertinent features of control acini (i.e., acini treated with no caerulein). In Fig. $3 a$ an acinus with its central lumen is shown. The nuclei are basally located and most of the cytoplasm is filled with rough endoplasmic reticulum and mitochondria. The zymogen granules are electron dense and located at the apical aspect of the cell. A higher magnification of the lumen of an acinus is shown in Fig. $3 \mathrm{~b}$. Of note are the numerous apical microvilli projecting into the lumen. Also discernable are the dense cytoskeletal structures beneath the apical plasmalemma. Further details of the apical cytoskeleton are illustrated in Fig. 3, $c$ and $d$. In $c$ sections of microvilli reveal the actin filaments that make up their cores. The interconnecting terminal web of microfilaments (actin) can be seen filling the area between the apical plasmalemma and the bands of intermediate filaments that parallel the lumen. In cross section this appears as a polygonal network. In the lower cell the band of intermediate filaments contains several electron-dense structures. Coursing obliquely between zymogen granules near the upper cell intermediate filament band is a microtubule (arrow).

Fig. $3 d$ shows a high magnification view of the relationships between a zymogen granule and the apical cytoskeleton.

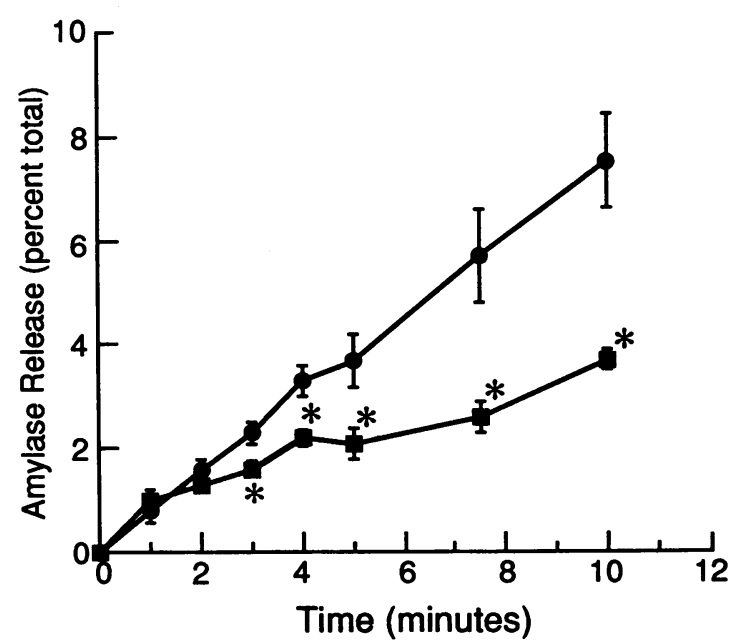

Figure 2. Time course of the effect of caerulein on amylase release from dispersed rat pancreatic acini. Aliquots of acinar suspension were incubated with either 0 (control), $0.1 \mathrm{nM}$, or $10 \mathrm{nM}$ caerulein. At the indicated times amylase release was measured in each aliquot as described in Methods. Values were determined as the amylase release measured in the aliquots containing $0.1 \mathrm{nM}(\bullet)$ or $10 \mathrm{nM}(\bullet)$ caerulein minus the amylase release measured in the control aliquot at each time point. Results are the means $\pm \mathrm{SE}$ of four experiments. * indicates that values for $10 \mathrm{nM}$ caerulein were statistically significantly less than the values for $0.1 \mathrm{nM}$ caerulein using the $t$ test for paired measurements $(P<0.05)$. 

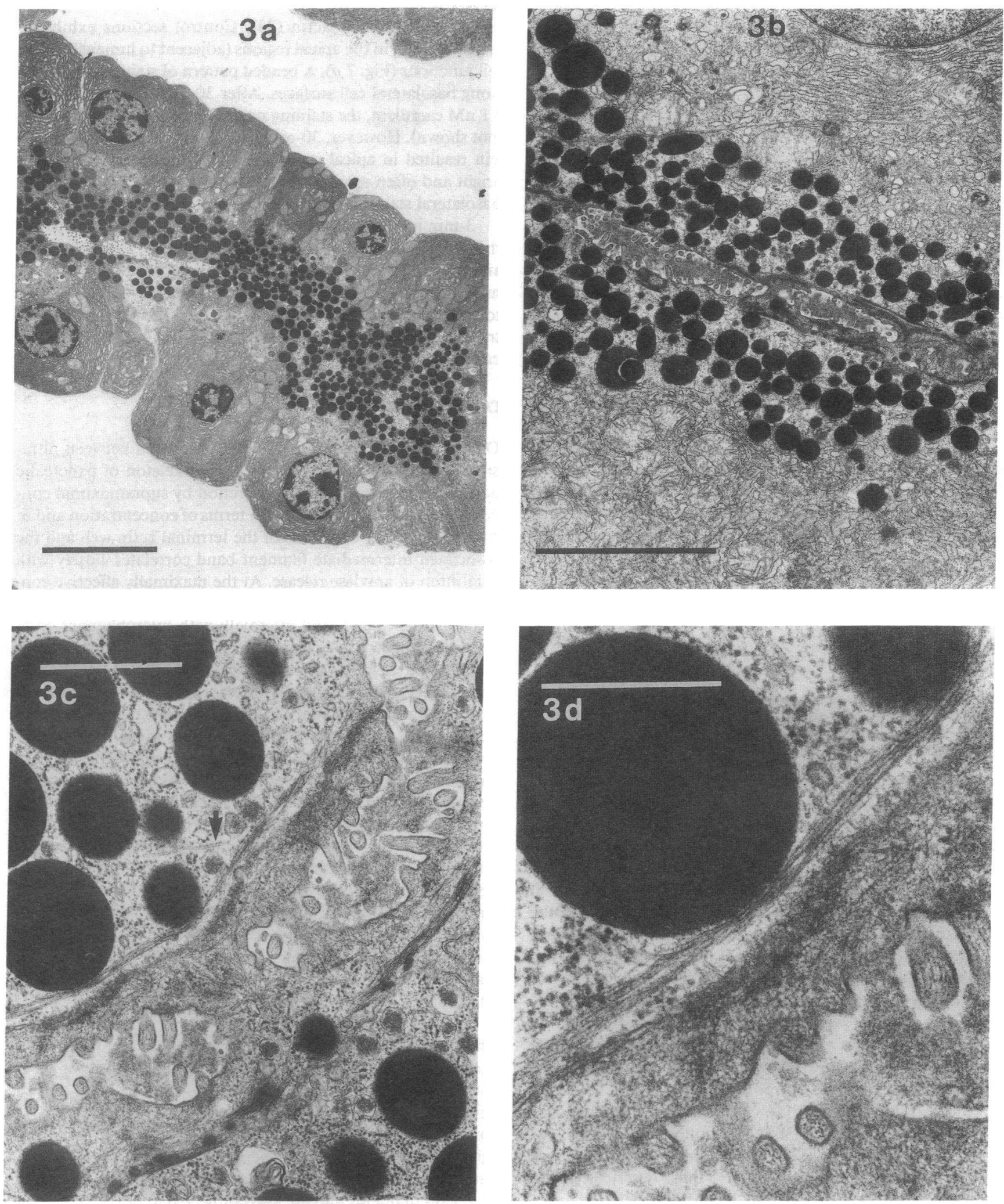

Figure 3. Electron micrographs of untreated acini. Micrographs are from dispersed acini that were incubated in incubation solution without caerulein for $30 \mathrm{~min}$. The acini were then prepared for electron microscopy as described in Methods. Scale bars: $a=10 \mu \mathrm{m} ; b=5 \mu \mathrm{m} ; c=1$ $\mu \mathrm{m} ; d=0.5 \mu \mathrm{m}$. The arrow in $c$ indicates a microtubule. See text for description.

The zymogen granule is abutting the intermediate filament band. In the adjacent apical microfilament web there is a curved, electron-dense collection limited to the region in prox- imity to the zymogen granule. There is a suggestion of structures traversing the gap between the intermediate filaments and the electron-dense material in the microfilament web. 
These structures may extend to the surface of the zymogen granule, as implied by irregularities in the portion of the granule periphery adjacent to the electron-dense collection.

In all experiments, observations in control acini revealed the terminal actin web and the microfilaments within the microvilli. The intermediate filament bands and the electrondense collections in intermediate filaments and in the terminal web were most obvious when the acinus was sectioned along the length of the lumen. In such sections, the electron-dense collections in the terminal web were usually present when a zymogen granule abutted the intermediate filament band. The cytoskeletal structures described in control acini were the same in acini incubated for $30 \mathrm{~min}$ with $1 \mathrm{pM}, 10 \mathrm{pM}$, and $0.1 \mathrm{nM}$ caerulein (not shown as micrographs).

Fig. 4 shows electron micrographs of acini incubated with $10 \mathrm{nM}$ caerulein for $30 \mathrm{~min}$. Striking at lower magnifications are blebs extending from the basolateral surface filled with cellular contents such as endoplasmic reticulum, mitochondria, and occasionally nuclei (the last not shown). In addition, no microvilli are discernable. Also illustrated are cytoplasmic vacuoles with somewhat irregular borders and contents of variable election density. These structures are located near Golgi cisternae and condensing vacuoles, and also are mixed among zymogen granules in the apical portion of the acinar cells. A higher magnification in Fig. $4 b$ again demonstrates no microvilli and the vacuoles with irregular contents. The electron micrographs in Fig. 4, $c$ and $d$ demonstrate that the microvilli are absent, there is no terminal microfilament web, and intermediate filament bands are not seen. Cytoplasmic structures such as ribosomes, rough endoplasmic reticulum, and zymogen granules fill the region normally occupied by the apical cytoskeleton. Irregular collections of electron-dense material bounded by a membrane are also seen in the upper left of Fig. $4 c$ and on the right of Fig. $4 d$. Of note, cytoskeleton can be seen at the sites of intercellular junctions, which appear intact. The lumens are generally filled with material of higher electron density than those of control acini. Fig. $4 d$ illustrates that even in acini sectioned along the long axis of the lumen, the terminal web and intermediate filament bands are absent.

In acini treated with $1 \mathrm{nM}$ caerulein, the changes in apical cytoskeleton are variable between cells. As seen in Fig. $5 a$, the upper acinar cell has a normal appearing apical cytoskeleton with intermediate filaments, terminal microfilament web, microvilli, and focal electron-dense structures. In the lower acinar cell neither the terminal web nor the intermediate filament band are seen. Also, few microvilli arise from the lower cell, yet the lumen is filled with microvilli. In contrast, the acinus in Fig. $5 b$ is nearly devoid of microvilli and little apical cytoskeleton is evident in any of the cells.

To determine the time course of the cytoskeletal changes, we studied acini after $3 \mathrm{~min}$ of incubation with $0,0.1 \mathrm{nM}$, and $10 \mathrm{nM}$ caerulein (Fig. 6). The electron micrographs of control and 0.1-nM specimens were similar to those described in Fig. 3. After $3 \mathrm{~min}$ of incubation with $10 \mathrm{nM}$ caerulein the apical cytoskeletal changes were fully developed; that is, there were few microvilli and there was an absence of intermediate filaments and terminal microfilament web. Some cytoskeleton could still be observed near the sites of intercellular junctions.

To further investigate the effects of caerulein on actin microfilaments, we studied frozen sections of pelletted acini stained with rhodamine-phalloidin, a fluorescent probe spe- cific for filamentous actin (23). Control sections exhibited bright staining in the apical regions (adjacent to lumens) and at cell junctions (Fig. $7 a$ ). A beaded pattern of staining appeared along basolateral cell surfaces. After 30-min incubations with $0.1 \mathrm{nM}$ caerulein, the staining pattern was essentially the same (not shown). However, 30-min incubations with $10 \mathrm{nM}$ caerulein resulted in apical staining that was either absent or less bright and often more narrow than in control acini (Fig. 7 b). Basolateral staining remained essentially unchanged.

3-min incubations with 0 and $0.1 \mathrm{nM}$ caerulein resulted in rhodamine-phalloidin staining patterns like 30-min control and $0.1 \mathrm{nM}$ caerulein. Incubation with $10 \mathrm{nM}$ caerulein for 3 min was sufficient to cause diminished apical staining similar to that seen with 30-min incubations with the same concentration. Again, the dotted basolateral staining was not significantly altered (not shown as micrographs).

\section{Discussion}

Our results demonstrate a striking correlation between ultrastructural alterations in the apical cytoskeleton of pancreatic acinar cells and inhibition of secretion by supramaximal concentrations of caerulein. Both in terms of concentration and in the temporal response, loss of the terminal actin web and the associated intermediate filament band correlates closely with inhibition of amylase release. At the maximally effective concentration of caerulein $(0.1 \mathrm{nM})$, the terminal web, intermediate filament band, and microvilli with microfilament cores are fully intact, as seen in control acini. All three of these cytoskeletal elements are essentially abolished at the fully inhibitory concentration of $10 \mathrm{nM}$ caerulein. These changes are also evident at $3 \mathrm{~min}$ of caerulein treatment, when the secretory rate is significantly different than that with $0.1 \mathrm{nM}$ caerulein. The rhodamine-phalloidin results substantiate the temporal and concentration relationship between the inhibition of secretion and alterations in the apical cytoskeleton. At the intermediate inhibitory concentration of $1 \mathrm{nM}$ caerulein, the ultrastructural alterations occur in some cells and not in others. If the cells with cytoskeletal alterations have inhibited secretion and the ultrastructurally normal cells respond to secretagogue maximally, the intermediate rate of amylase release would be explained. In sum, these results suggest that the inhibitory effects of supramaximally effective concentrations of caerulein result from their effects on the apical cytoskeletal structures.

The electron-dense regions in the terminal actin web and the adjacent intermediate filament band have not been previously described. The observation of interconnecting structures between the dense region of the terminal web and the intermediate filament band with a closely approximated zymogen granule is also novel. Morphologically, these dense regions somewhat resemble the dense bodies seen in smooth muscle cells (24). Those dense bodies serve as anchor points for actin filaments and are also connected to other cytoskeletal elements.

Despite evidence in the literature that dehydration and fixation procedures cause destruction of cytoskeletal elements (25), the visualization of the apical cytoskeleton in our electron micrographs appears more detailed than many published results. Although the modified Karnovsky's fixative is different than the routine formaldehyde often used, the post-fixa- 

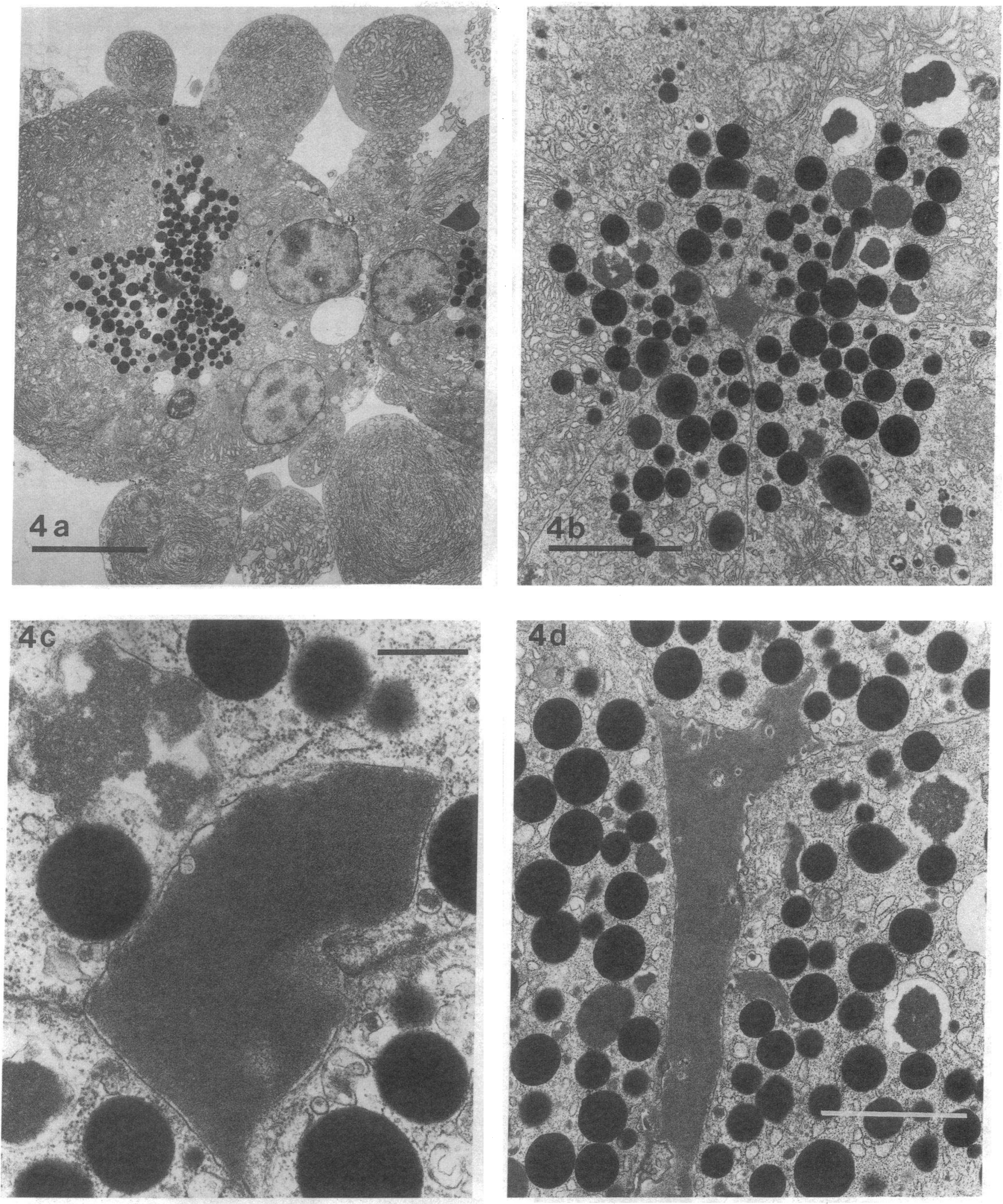

Figure 4. Effects of a 30-min incubation with $10 \mathrm{nM}$ caerulein on dispersed acini. Scale bars: $a=10 \mu \mathrm{m} ; b=3 \mu \mathrm{m} ; c=0.5 \mu \mathrm{m} ; d=2 \mu \mathrm{m}$. See text.

tion with $\mathrm{OsO}_{4}$, dehydration, embedding, and staining procedures we used are fairly standard. The use of bismuth rather than lead as one of the stains is a slight divergence from common procedures. It is uncertain whether our methodology al- lowed the appearance of the electron-dense regions within the terminal web and apical intermediate filament bands, but they were a consistent finding in control acini and in those incubated with $0.1 \mathrm{nM}$ caerulein or less. 

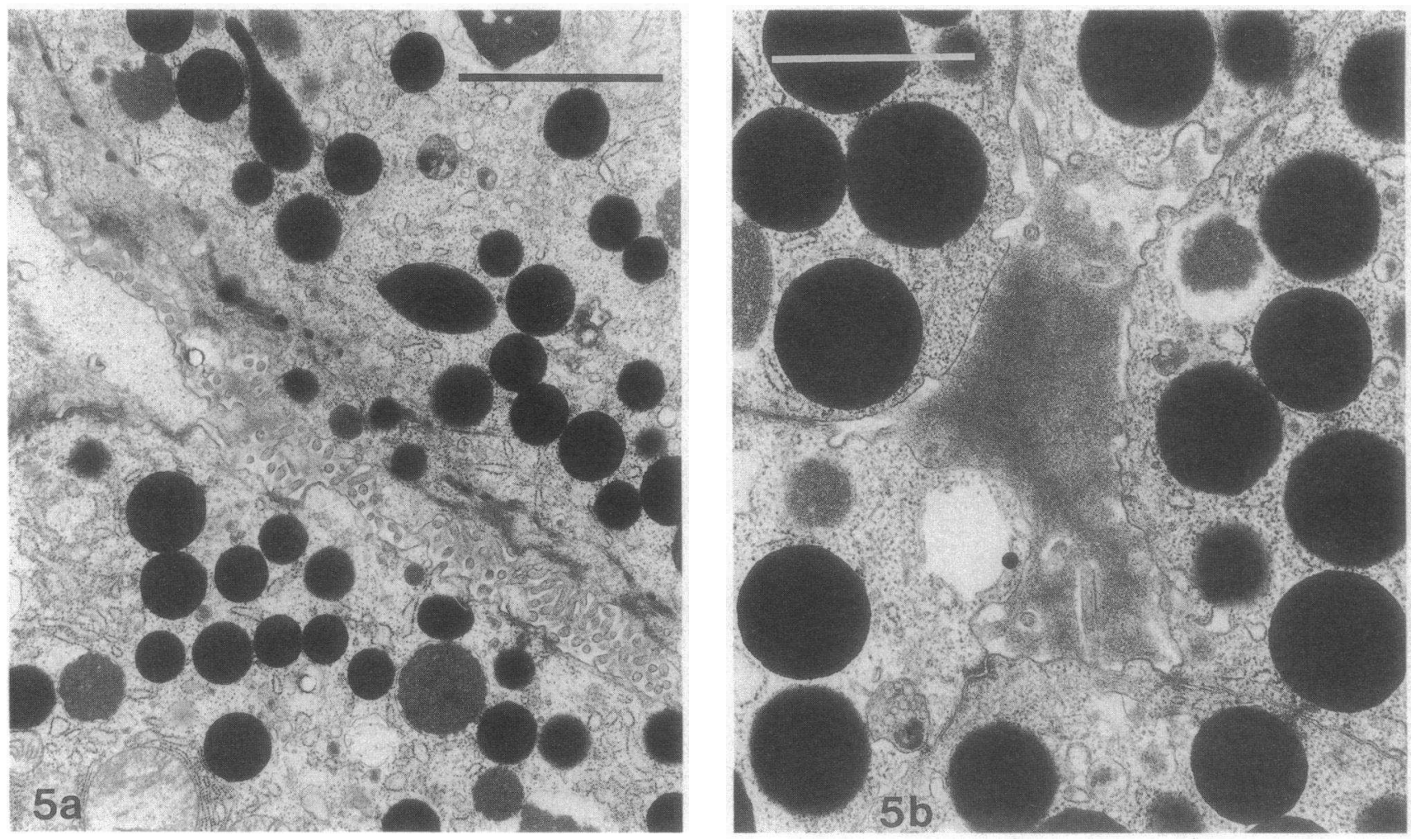

Figure 5. Effects of a 30-min incubation with $1.0 \mathrm{nM}$ caerulein on dispersed acini. Scale bars: $a=2 \mu \mathrm{m} ; b=1 \mu \mathrm{m}$. See text.
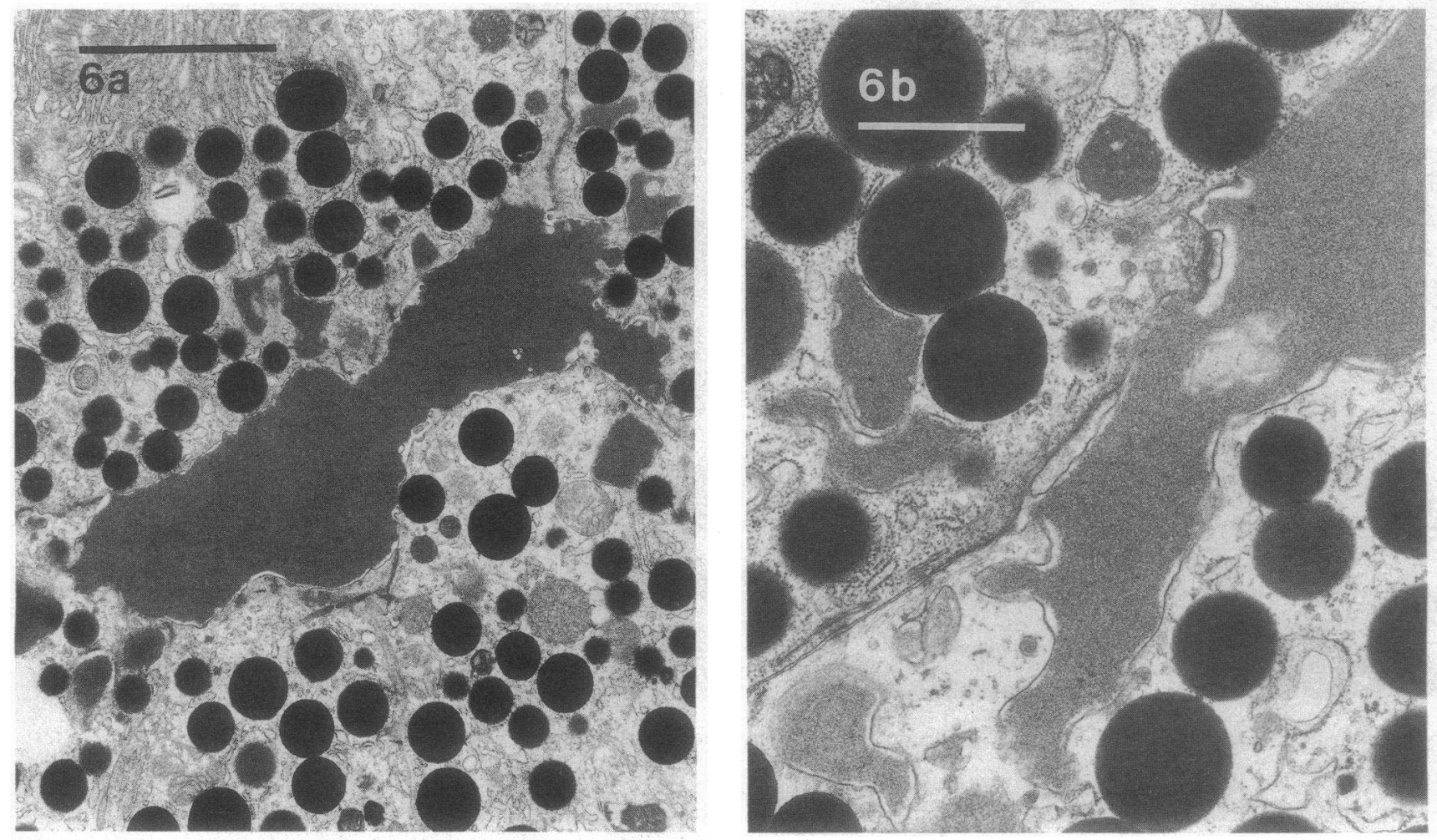

Figure 6. Effects of a 3-min incubation with $10 \mathrm{nM}$ caerulein on dispersed acini. Scale bars: $a=3 \mu \mathrm{m} ; b=1 \mu \mathrm{m}$. See text. 

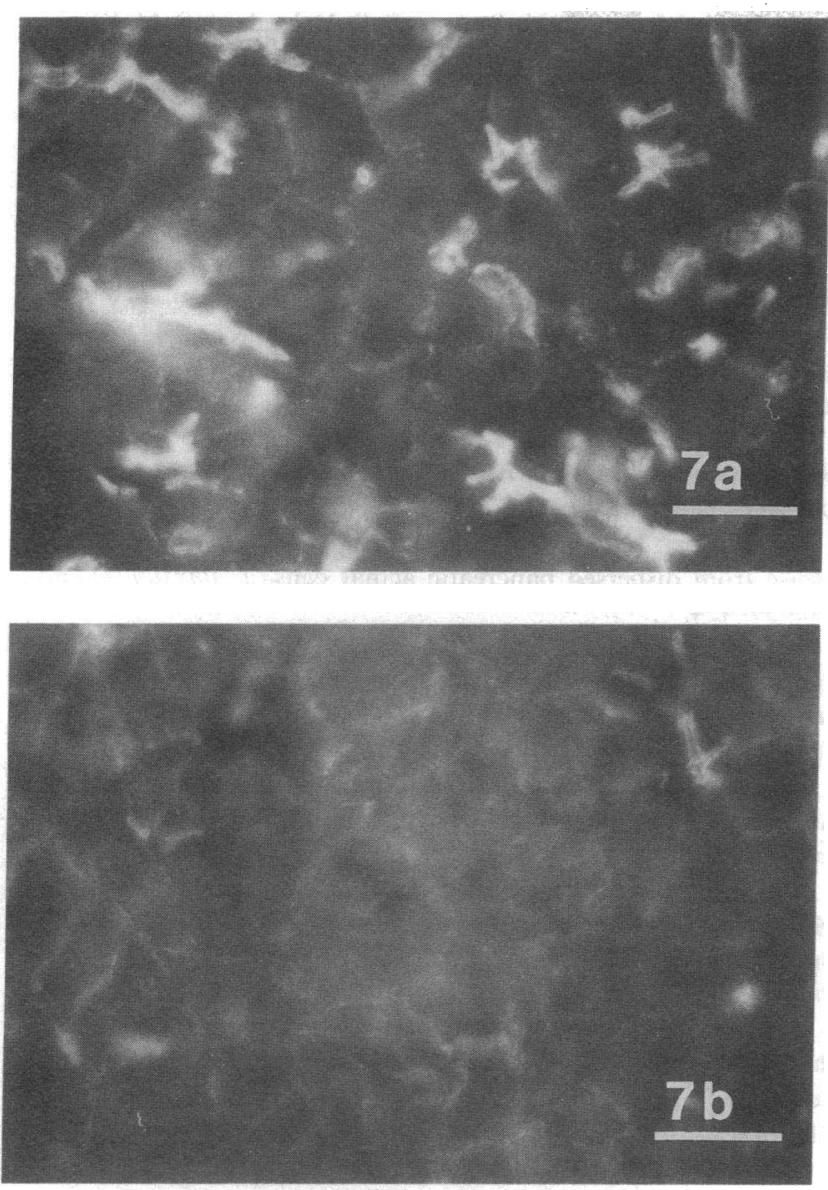

Figure 7. Effects of caerulein on actin filament staining with rhodamine-phalloidin. Dispersed acini were incubated with either $0(a)$ or $10 \mathrm{nM}(b)$ caerulein for $30 \mathrm{~min}$. The acini were prepared for actin filament staining as described in Methods. Scale bars: $a$ and $b=20$ $\mu \mathrm{m}$. See text.

It has previously been suggested that cytoskeletal elements may be important in the process of secretion. Orci et al. (17) observed that concentrations of cytochalasin B (a toxin that results in a net loss of microfilaments) that enhanced glucoseinduced insulin secretion by rat pancreatic beta cells produced alterations in the cortical microfilamentous web of islet cells. They postulated that the actin web might have a role in controlling the access of insulin granules to the cell membrane. Williams (26) showed that cytochalasin B caused the disappearance of the apical microfilamentous web and the microvilli in murine pancreatic fragments and isolated pancreatic acini. These changes were accompanied by a reduction in bethanechol-stimulated amylase release without alteration of basal amylase release. Interestingly, bethanechol-stimulated amylase from single isolated acinar cells, which have lost most of their apical specialization of microvilli and terminal web in the process of separation, was not affected by cytochalasin $B$. Stock and co-workers (27) also noted disruption of the terminal web and decreased number of microvilli in pieces of rat pancreas treated with cytochalasin B. These changes were associated with inhibition of caerulein-stimulated amylase and lipase release, and reduced morphologic evidence of exocytosis. Our results concur with both of these studies utilizing cytochalasin B in implying that the terminal web is important in normal pancreatic secretion. Investigations using this toxin are potentially limited by the effects of cytochalasin on other cell processes, however.

Several of the ultrastructural changes observed in this study have been described previously. Lampel and Kern (28) infused rats with high doses of caerulein, and observed ultrastructural changes including formation of cytoplasmic vacuoles in the acinar cells, perhaps due to premature fusion of condensing vacuoles and secretory granules in the region of the Golgi complex. With prolonged stimulation, large cytoplasmic vacuoles (or "lakes") apparently evolve from enlarging vacuoles, and evidence of autophagy was observed. Vacuole fusion with the basolateral membrane was also observed, as was reduced apical exocytosis. The ultrastructural changes were associated with pancreatic inflammation and reduced carbamylcholinestimulated amylase release. Savion and Selinger (29) noted similar morphologic changes after stimulation of rat pancreatic slices with supramaximal (e.g., inhibitory) concentrations of CCK or carbamylcholine. They found that inhibitory doses produced reduction in the size of the lumen and "plugging" with electron-dense secretory material. They also made specific note of disruption of the terminal microfilament web. In contrast, Burnham and Williams (30) found little effect on microvilli or cellular structures surrounding the lumen. Watanabe et al. (31) also noted large vacuole formation in acinar cells of rats infused with supramaximal doses of caerulein and found that both lysosomal and digestive enzymes were present in the vacuoles. They suggested that this "crinophagy" was important in the initiation of pancreatitis, since mixing of lysosomal hydrolases and zymogens may result in the activation of the digestive enzymes. Our finding of multiple membranebound cytoplasmic structures with contents of variable electron density near the Golgi area and in the apical portions of cells treated with supramaximal concentrations of caerulein is morphologically consistent with this hypothesis. Cytoplasmic protrusions (blebs) from the basolateral membrane of dispersed acini stimulated with supramaximal concentrations of caerulein have also been observed by others $(30,32)$.

The intracellular biochemical mechanisms that mediate the effect of caerulein on the apical cytoskeleton of the pancreatic acinar cell are not established. Caerulein and other CCK analogues stimulate both the metabolism of cellular phospholipids and calcium. In particular, these agonists cause a phospholipase C-mediated breakdown of phosphoinositides leading to the formation of 1,2-diacylglycerol and inositol phosphates $(3,8,11,12,14,16,33,34)$. One inositol phosphate, inositol 1,4,5-trisphosphate, mediates release of calcium from intracellular stores (34-36), leading to an increase in free intracellular calcium $(2,9,10,13,15)$. The other metabolite, 1,2-diacylglycerol, activates protein kinase $C$ and modulates the secretory response (12).

Of particular interest to the observations in this article, we have found that supramaximally effective concentrations of CCK analogues (i.e., concentrations that are inhibitory for secretion) cause a several-fold greater decrease in the phosphoinositides and increase in 1,2-diacylglycerol than maximally effective concentrations $(3,9,14)$. One of the phosphoinositides, phosphatidylinositol 4,5-bisphosphate, has been demonstrated to polymerize actin by dissociating prolifin:actin complexes $(37,38)$ and stabilize actin filament net- 
works by its ability to inhibit the actin filament-severing properties of gelsolin (39-41). In contrast, $\mathrm{Ca}^{2+}$ activates the severing properties of gelsolin (42-45). Thus, the effects of supramaximally effective concentrations of caerulein on the apical actin filament network may be mediated by the effects of the caerulein-induced changes in phosphatidylinositol 4,5bisphosphate and $\mathrm{Ca}^{2+}$ on gelsolin and prolifin:actin complexes.

\section{Acknowledgments}

We wish to thank Dr. Penny Sue Perkins, Dr. Jerry Vande Berg, Dr. Mark Ellisman, Dr. Daniel Mercola, Dr. Katsumi Miyai, and Abbyann Sisk for valuable advice and technical assistance. We also thank Lisa Y. Nelson for typing the manuscript.

\section{References}

1. Jensen, R. T., G. F. Lemp, and J. D. Gardner. 1980. Interaction of cholecystokinin with specific membrane receptors on pancreatic acinar cells. Proc. Natl. Acad. Sci. USA. 77:2079-2083.

2. Bruzzone, R., T. Pozzon, and C. B. Wollheim. 1986. Caerulein and carbamylcholine stimulate pancreatic amylase release at resting cytosolic free $\mathrm{Ca}^{2+}$. Biochem. J. 235:139-143.

3. Dixon, J. F., and L. E. Hokin. 1984. Secretagogue-stimulated phosphatidylinositol breakdown in the exocrine pancreas liberates arachidonic acid, stearic acid and glycerol by sequential actions of phospholipase C and diglyceride lipase. J. Biol. Chem. 259:14418-14425.

4. Halenda, S. P., and R. P. Rubin. 1982. Phospholipid turnover in isolated rat pancreatic acini: consideration of the relative roles of phospholipase $A_{2}$ and phosphlipase C. Biochem. J. 208:713-721.

5. Hokin, L. E., and M. R. Hokin. 1958. Phosphoinositides and protein secretion in the pancreas. J. Biol. Chem. 233:805-810.

6. Hokin, M. R., and L. E. Hokin. 1953. Enzyme secretion and the incorporation of ${ }^{32} \mathrm{P}$ into phospholipids of pancreas slices. J. Biol. Chem. 203:967-977.

7. Hokin, M. R., and L. E. Hokin. 1954. Effects of acetylcholine on phospholipids in the pancreas. J. Biol. Chem. 209:549-558.

8. Hokin-Neaverson, M. 1974. Acetylcholine causes a net decrease in phosphatidylinositol and a net increase in phosphatidic acid in mouse pancreas. Biochem. Biophys. Res. Commun. 58:763-768.

9. Merritt, J. E., and R. P. Rubin. 1985. Pancreatic amylase secretion and cytoplasmic free calcium. Biochem. J. 230:151-159.

10. Ochs, D. L., J. I. Korenbrot, and J. A. Williams. 1985. Relationship between free cytosolic calcium and amylase release by pancreatic acini. Am. J. Physiol. 249:G389-G398.

11. Orchard, J. L., J. S. Davis, R. E. Larson, and R. V. Farese. 1984 Effects of carbachol and pancreozymin (cholecystokinin-octapeptide) on polyphosphoinositide metabolism in the rat pancreas in vitro. Biochem. J. 217:281-287.

12. Pandol, S. J., and M. S. Schoeffield. 1986. 1,2-diacylglycerol, protein kinase $\mathrm{C}$ and pancreatic enzyme secretion. J. Biol. Chem. 261:4438-4444.

13. Pandol, S. J., M. S. Schoeffield, G. Sachs, and S. Muallem. 1985. Role of free cystolic calcium in secretagogue-stimulated amylase release from dispersed acini from guinea pig pancreas. J. Biol. Chem. 260:10081-10086.

14. Pandol, S. J., M. W. Thomas, M. S. Schoeffield, G. Sachs, and S. Muallem. 1985. Role of calcium in cholecystokinin-stimulated phosphoinositide breakdown in exocrine pancreas. Am. J. Physiol. 248:G551-G560.

15. Powers, R. E., P. C. Johnson, M. J. Houlihan, A. K. Saluja, and M. L. Steer. 1985. Intracellular $\mathrm{Ca}^{2+}$ levels and amylase secretion in quin 2-loaded mouse pancreatic acini. Am. J. Physiol. 248:C535C542.
16. Putney, J. W., G. M. Burgess, S. P. Halenda, J. S. McKinney, and R. P. Rubin. 1983. Effects of secretagogues on $\left.{ }^{32} \mathrm{P}\right]$ phosphatidylinositol 4,5-bisphosphate metabolism in the exocrine pancreas. Biochem. J. 212:483-488.

17. Orci, L., K. H. Gabbay, and W. J. Malaisse. 1972. Pancreatic beta-cell web: its possible role in insulin secretion. Science (Wash. DC) 175:1128-1130.

18. Palade, G. E. 1975. Intracellular aspects of the process of protein secretion. Science (Wash. DC). 189:347-358.

19. Pandol, S. J., R. T. Jensen, and J. D. Gardner. 1982. Mechanism of $\left[\mathrm{Tyr}^{4}\right]$ bombesin-induced desensitization in dispersed acini from guinea pig pancreas. J. Biol. Chem. 257:12024-12029.

20. Peiken, S. R., A. J. Rottman, S. Batzri, and J. D. Gardner. 1978. Kinetics of amylase release by dispersed acini prepared from guinea pig pancreas. Am. J. Physiol. 235:E743-E749.

21. Gardner, J. D., and M. J. Jackson. 1977. Regulation of amylase release from dispersed pancreatic acinar cells. J. Physiol. (Lond.) 270:439-454.

22. Drenckhahn, D., and H. G. Mannherz. 1983. Distribution of acin and the actin-associated proteins myosin, tropomyosin, alpha-actinin, vinculin, and villin in rat and bovine exocrine glands. Eur. $J$. Cell Biol. 30:167-176.

23. Wulf, E., A. Deboben, F. A. Bautz, H. Faulstick, and T. Wieland. 1979. Fluorescent phallotoxin, a tool for the visualization of cellular actin. Proc. Natl. Acad. Sci. USA. 76:4498-4502.

24. Gabella, G. 1981. Structure of smooth muscles. In Smooth Muscle: An Assessment of Current Knowledge. E. Bulbring, A. F. Brading, A. W. Jones, and T. Tomita, editors. University of Texas Press, Austin. 1-46.

25. Small, J. V., and G. Langanger. 1981. Organization of actin in the leading edge of cultured cells. Influence of osmium tetroxide and dehydration on the ultrastructure of actin meshworks. J. Cell Biol. 91:695-705.

26. Williams, J. A. 1977. Effects of cytochalasin B on pancreatic acinar cell structure and secretion. Cell Tissue Res. 179:453-466.

27. Stock, C., J. F. Launay, J. F. Grenier, and H. Bauduin. 1978. Pancreatic acinar cell changes induced by caerulein, vinblastine, deuterium oxide, and cytochalasin B in vitro. Lab. Invest. 38:157-164.

28. Lampel, M., and H. F. Kern. 1977. Acute interstitial pancreatitis in the rat induced by excessive doses of a pancreatic secretagogue Virchows Arch. A. Pathol. Anat. Histol. 373:97-117.

29. Savion, N., and Z. Selinger. 1978. Morphological changes in rat pancreatic slices associated with inhibition of enzyme secretion by high concentrations of secretagogue. J. Cell Biol. 76:467-482.

30. Burnham, D. B., and J. A. Williams. 1982. Effects of high concentrations of secretagogues on the morphology and secretory activity of the pancreas: a role for microfilaments. Cell Tissue Res. 222:201-212.

31. Watanabe, O., F. M. Baccino, M. L. Steer, and J. Meldolesi. 1984. Supramaximal caerulein stimulation and ultrastructure of rat pancreatic acinar cell: early morphological changes during development of experimental pancreatitis. Am. J. Physiol. 246:G457-G467.

32. Adler, G., H. F. Kern, G.-Z. Pan, and J. D. Gardner. 1984. Secretagogue-induced membrane alterations in dispersed acini from rat pancreas. Eur. J. Cell Biol. 33:234-241.

33. Rubin, R. P., P. P. Godfrey, D. A. Chapman, and J. W. Putney. 1984. Secretagogue-induced formation of inositol phosphates in exocrine pancreas: implications for a messenger role for inositol triphosphate. Biochem. J. 219:655-659.

34. Streb, H., J. P. Heslop, R. F. Irvine, I. Schultz, and M. J. Berridge. 1985. Relationship between secretagogue-induced $\mathrm{Ca}^{2+}$ release and inositol phosphate production in permeabilized pancreatic acinar cells. J. Biol. Chem. 260:7309-7315.

35. Muallem, S., M. Schoeffield, S. Pandol, and G. Sachs. 1985. Inositol triphosphate modification of ion transport in rough endoplasmic reticulum. Proc. Natl. Acad. Sci. USA. 82:4433-4437. 
36. Streb, H., R. F. Irvine, M. J. Berridge, and I. Schultz. 1983. Release of $\mathrm{Ca}^{2+}$ from a nonmitochondrial intracellular store in pancreatic acinar cells by inositol-1,4,5-triphosphate. Nature (Lond.). 306:67-69.

37. Lassing, I., and U. Lindberg. 1985. Specific interaction between phosphatidylinositol 4,5-bisphosphate and profilactin. Nature (Lond.). 314:472-474.

38. Lassing, I., and U. Lindberg. 1988. Specificity of the interaction between phosphatidylinositol 4,5-bisphosphate and the profilin: actin complex. J. Cell. Biochem. 37:255-267.

39. Janmey, P. A., K. Iida, H. L. Yin, and T. P. Stossel. 1987. Polyphosphoinositide micelles and polyphosphoinositide-containing vesicles dissociate endogenous gelsolin-actin complexes and promote actin assembly from the fast growing end of actin filaments blocked by gelsolin. J. Biol. Chem. 262:12228-12236.

40. Janmey, P. A., and T. P. Stossel. 1987. Modulation of gelsolin function by phosphatidylinositol 4,5-bisphosphate. Nature (Lond.). 325:362-364.

41. Yin, H. L., K. Iida, and P. A. Janmey. 1988. Identification of a polyphosphionositide-modulated domain in gelsolin which binds to the sides of actin filaments. J. Cell Biol. 106:805-812.

42. Bryan, J., and M. Kurth. 1984. Actin-gelsolin interactions: evidence for two actin-binding sites. J. Biol. Chem. 259:7480-7487.

43. Bryan, J., and L. M. Coluccio. 1985. Kinetic analysis of F-actin depolymerization in the presence of platelet gelsolin and gelsolin-actin complexes. J. Cell Biol. 101:1236-1244.

44. Janmey, P. A., C. Chaponnier, S. E. Lind, K. S. Zaner, T. P. Stossel, and H. L. Yin. 1985. Interactions of gelsolin and gelsolin-actin complexes with actin: effects of calcium on actin nucleation, filament severing and end blocking. Biochemistry. 24:3714-3723.

45. Yin, H. L., and T. P. Stossel. 1979. Control of cytoplasmic actin gel-sol transformation by gelsolin, a calcium-dependent regulatory protein. Nature (Lond.). 281:583-586. 